\title{
CARACTERIZAÇÃO DE COMPOSTOS DE RESÍDUOS SÓLIDOS URBANOS ORGÂNICOS DE UNIDADES DE RECICLAGEM E COMPOSTAGEM DOS MUNICÍPIOS DE SÃO PAULO E DE SÃO JOSÉ DOS CAMPOS
}

\section{CHARACTERIZATION OF ORGANIC SOLID URBAN WASTE COMPOSTS FROM THE RECYCLING AND COMPOSTING PLANTS OF SÃO PAULO AND SÃO JOSÉ DOS CAMPOS MUNICIPALITIES}

\section{Cassio Hamilton Abreu-Junior ${ }^{1}$; Antonio Carlos Basso ${ }^{2}$; José Carlos Chitolina ${ }^{3}$; Fábio Cesar Silva ${ }^{4}$; Keyla Boralli ${ }^{5}$; Carolina Façanha Wendel ${ }^{6}$}

${ }^{1}$ Professor do Centro de Energia Nuclear na Agricultura - CENA/USP, Caixa Postal 96, 13400-970 - Piracicaba, SP. E-mail: cahabreu@cena.usp.br

${ }^{2}$ Diretor e Professor da Escola de Engenharia de Piracicaba - Fundação Municipal de Ensino de Piracicaba - FUMEP, Caixa Postal 226, 13414-040 - Piracicaba, SP.

$$
\text { E-mail: jcchito@yahoo.com.br }
$$

${ }^{3}$ Professor da Escola de Engenharia de Piracicaba - Fundação Municipal de Ensino de

Piracicaba - FUMEP, Caixa Postal 226, 13414-040 - Piracicaba, SP.

${ }^{4}$ Pesquisador da Embrapa Informática Agropecuária e professor da Fatec Piracicaba, Caixa Postal 6041 - 13083-886 - Campinas, SP. E-mail: fcesar@cnptia.embrapa.br

${ }^{5}$ Aluno de Iniciação Científica do Centro Energia Nuclear na Agricultura -

CENA/USP, Caixa Postal 96 - CEP. 13400-970 - Piracicaba, SP.

E-mail: kcarolinab@gmail.com

${ }^{6}$ Aluno do Programa de Pós-Graduação em Energia Nuclear na Agricultura -

CENA/USP, Caixa Postal 96 - CEP. 13400-970 - Piracicaba, SP.

E-mail: carolwendel@gmail.com

\begin{abstract}
RESUMO
A compostagem de resíduos sólidos urbanos é importante para uma gestão ambiental sustentável. Tal prática reduz o volume e a carga de resíduos que são enviados para os aterros sanitários. Objetivou-se, com este estudo, avaliar a qualidade de compostos de resíduos urbanos produzidos nas usinas de reciclagem e compostagem (URC) de São Matheus, Vila Leopoldina e São José dos Campos, SP. Durante nove meses, foram coletadas amostras dos compostos originais oriundos do sistema DANO de pré-tratamento de cada URC. Para se avaliar o grau de maturação e qualidade dos compostos, uma fração das amostras originais foi compostada por mais 150 dias. Foram comparados os teores de carbono orgânico, nutrientes e metais pesados entre compostos originais e
\end{abstract}


maturados. Os compostos produzidos nas URCs São Matheus e Vila Leopoldina apresentavam baixo grau de maturação, ou seja, representavam os respectivos resíduos sólidos urbanos. Contudo, quando estes resíduos foram devidamente compostados, proporcionaram compostos com teores de carbono orgânico $\left(>150 \mathrm{~g} \mathrm{~kg}^{-1}\right)$ adequados para o registro como fertilizante orgânico classe C. Todos os compostos apresentaram ampla variabilidade temporal na composição química, com teores mínimos de $\mathrm{Ca}$ e $\mathrm{Fe}$ adequados para serem declarados como fonte destes nutrientes e o teor de Cr abaixo do limite máximo admitido pela legislação. Não obstante, somente o composto da UCR São José dos Campos, oriundo de coleta seletiva, apresentou teores de $\mathrm{Cd}, \mathrm{Ni}$ e $\mathrm{Pb}$ adequados para classificação como fertilizante orgânico. Concluiu-se que a coleta seletiva dos resíduos sólidos urbanos orgânicos e a compostagem com critérios técnicos são procedimentos essenciais para a obtenção de composto com propriedades adequadas para enquadrá-lo como fertilizante orgânico, agregando valor econômico aos processos, e tornando a gestão dos resíduos sólidos urbanos viável economicamente.

Palavras-chave: Compostagem. Legislação sobre fertilizante orgânico. Metais pesados. Política nacional de resíduo sólido.

\begin{abstract}
Composting of solid urban waste has an important role for sustainable environmental management of solid waste generated in cities by reducing the load and volume of waste sent to landfills. The objective of this study was to evaluate the quality of the urban waste composts produced in the units of recycling and composting plants (URC) of São Matheus, Vila Leopoldina and São José dos Campos, SP. During nine months, samples were collected from the original materials given by the pretreatment DANO system of each URC. In order to evaluate the maturation grade and quality of the composts, a fraction of the original samples was composted for 150 days. The concentrations of organic carbon, nutrients and heavy metals were compared between the original and maturated composts. The composts produced in the São Matheus and Vila Leopoldina URCs had a low maturation grade, in other words, they represented their own municipal solid wastes. However, when these wastes were properly composted, they provided composts with organic carbon concentrations ( $>150 \mathrm{~g} \mathrm{~kg}^{-1}$ ) suitable to be registered as class $\mathrm{C}$ organic fertilizers. All composts presented wide temporal variability in the chemical composition, with minimum concentrations of $\mathrm{Ca}$ and $\mathrm{Fe}$ enough to be declared as the source of these nutrients, and the Cr concentration below the maximum limit allowed by legislation. Nevertheless, only the São José dos Campos URC compost, coming from a selective collection, presented concentration of $\mathrm{Cd}, \mathrm{Ni}$ and $\mathrm{Pb}$ suitable for classification as an organic fertilizer. It was concluded that the selective collection of organic solid urban waste and composting based on technical criteria are essential procedures for obtaining composts with appropriate properties to frame it as organic fertilizer. These procedures give economic value to the process, and make the management of solid urban waste economically viable.
\end{abstract} Keywords: Composting. Directive on organic fertilizer. heavy metal. National policy on solid waste.

\title{
1. INTRODUÇÃO
}

Há um aumento continuo na quantidade de resíduo sólido urbano produzido devido à atividade humana e ao crescimento populacional. Este resíduo, quando disposto de forma inadequada, pode causar prejuízo ao ambiente e à saúde humana (MELO et al., 1997; CRAVO et al., 1998; ABREU-JUNIOR et al., 2005; SILVA et al., 2005, 2009; LAVAGNOLO, 2012). O gerenciamento adequado do resíduo sólido urbano sempre será um problema atual, caro e 
desafiador, colocando em confronto os reguladores ambientais para atender a política nacional de resíduos, as autoridades locais e o bem-estar do cidadão (ABREU-JUNIOR et al., 2009a).

As práticas até então tidas como usuais de disposição, sejam aterros controlados ou mesmo despejos ilegais a céu aberto, produzem impactos ambientais indesejáveis; além de se constituírem, frequentemente, em focos de problemas de saúde pública, devido à contaminação das águas superficiais e subterrâneas e à proliferação de animais e insetos vetores de doenças. Os aterros sanitários, projetados para que não existam esses impactos negativos, são de custo a cada dia mais proibitivo. O tratamento racional do resíduo sólido urbano consiste, basicamente, na separação da fração orgânica compostável dos materiais orgânicos recalcitrantes (papel, papelão e plástico) e inertes (vidro, material ferroso e outros), ambos recicláveis, e do rejeito. Assim, considerando os elevados custos ambientais, econômicos e sociais, a destinação dos resíduos sólidos urbanos orgânicos para unidades de compostagem se constitui na melhor opção para diminuir os custos e a vida útil dos aterros sanitários (HARGREAVES et al., 2008; ABREU-JUNIOR et al., 2009a; LAVAGNOL, 2012), reduzindo o volume final de resíduos urbanos encaminhados para os aterros, conforme passou a ser preconizado pela Política Nacional de Resíduos Sólidos de 2010 (BRASIL, 2010), e propiciando matéria orgânica e nutrientes ao solo agrícola.

O resíduo sólido urbano é problema de competência de saneamento ambiental, de responsabilidade do governo municipal, mas, na medida em que sofre compostagem, o composto de resíduo sólido urbano orgânico tornar-se passível de ser produto registrado como fertilizante orgânico classe C, conforme estabelecido pela Instrução Normativa (IN) no 25 de 2009, do Ministério da Agricultura, Pecuária e Abastecimento - MAPA (BRASIL, 2009). Desta forma, parte do problema torna-se produto com valor agregado.

Para o registro do composto de resíduo sólido urbano orgânico como fertilizante orgânico classe C (BRASIL, 2009), o composto deve apresentar as seguintes características, em porcentagem mássica $\left(\%, \mathrm{~m} / \mathrm{m}\right.$, expressos em base seca, exceto a umidade): umidade determinada a $65^{\circ} \mathrm{C} \leq 50 \%$, nitrogênio total $\geq 0,5 \%$, carbono orgânico $\geq 15 \%$, capacidade de troca de cátions (CTC) a pH 7 conforme declarado, valor de $\mathrm{pH}$, em solução de $\mathrm{CaCl}_{2} \quad 0,01 \mathrm{~mol} \mathrm{~L}^{-1} \geq 6,5$, relação $\mathrm{C} / \mathrm{N} \leq 20$, relação $\mathrm{CTC} / \mathrm{C}$ conforme declarado e outros nutrientes conforme declarado. Os nutrientes cálcio $(\mathrm{Ca})$, magnésio $(\mathrm{Mg})$, enxofre $(\mathrm{S})$, boro $(\mathrm{B})$, cloro $(\mathrm{Cl})$, cobalto $(\mathrm{Co})$, cobre $(\mathrm{Cu})$, ferro $(\mathrm{Fe})$, manganês $(\mathrm{Mn})$, níquel $(\mathrm{Ni})$, molibdênio $(\mathrm{Mo})$, silício $(\mathrm{Si})$ e de zinco $(\mathrm{Zn})$, quando declarados, devem respeitar os seguintes teores mínimos garantidos, em $\%(\mathrm{~m} / \mathrm{m}$, expressos em base seca): 1,0; 1,$0 ; 1,0 ; 0,03 ; 0,1 ; 0,005 ; 0,05 ; 0,2 ; 0,05 ; 0,005 ; 0,005 ; 1,0 ; 0,1 ;$ respectivamente. As análises dos fertilizantes orgânicos devem seguir protocolos análogos aos descrito no Manual de Métodos Analíticos Oficiais para Fertilizantes Minerais, Orgânicos, Organominerais e Corretivos, do MAPA (BRASIL, 2007).

A aplicação de composto de resíduo sólido urbano na agricultura tem-se mostrado como uma importante fonte de nutrientes para as plantas e um excelente melhorador das propriedades biológicas, físicas e químicas do solo (MELO et al., 1997; OLIVEIRA, 2000; ABREU-JUNIOR et al., 2005, 2009a; HARGREAVES et al., 2008). Todavia, quando o composto utilizado não for adequado e, ou, a taxa de aplicação exceder aquela definida pelo critério do nitrogênio disponível (CONAMA, 2006), geralmente doses superiores a $50 \mathrm{tha}^{-1}$ na base seca, há a possibilidade de contaminação do solo e das plantas por metais pesados (HE et al., 1992, 1995; JORDÃO et al., 1996; CRAVO et al., 1998; EGREJA FILHO et al., 1999; OLIVEIRA, 2000) e dos lençóis freáticos por lixiviação de nitrato resultante da mineralização do composto, não obstante aos problemas de salinização, de dispersão dos colóides e de redução da condutividade hidráulica do solo (MELO et al., 1997; OLIVEIRA, 2000; ABREU-JUNIOR et al., 2005, 2009a).

Assim, uma das principais preocupações com o uso de composto de resíduo sólido urbano na agricultura é consequência dos teores de metais pesados que o produto possa conter (SILVA et al., 2005; ABREU-JUNIOR et al., 2005; 2009a). Os metais pesados, termo que inclui desde 
micronutrientes de plantas a metais intrinsecamente tóxicos, estão envolvidos em um sistema complexo de reações que ocorrem no solo, podendo contaminar o ambiente e entrar na cadeia alimentar (HE et al., 1992; MELO et al., 1997; CRAVO et al., 1998; OLIVEIRA, 2000); não obstante seja relatado que apenas uma pequena fração dos metais se apresenta em formas prontamente disponíveis às plantas (JORDÃO et al., 1996; EGREJA FILHO et al., 1999). Para compostos de resíduo sólido urbano, ou seja, os fertilizantes orgânicos classe $\mathrm{C}$, conforme a Instrução Normativa MAPA n ${ }^{\circ} 27$ de 2006 (BRASIL, 2006), os limites máximos de contaminantes admitidos são: arsênio (As) $\leq 20,00 \mathrm{mg} \mathrm{kg}^{-1}$, cádmio $(\mathrm{Cd}) \leq 3,00 \mathrm{mg} \mathrm{kg}^{-1}$, chumbo $(\mathrm{Pb}) \leq 150,00$ $\mathrm{mg} \mathrm{kg}^{-1}$, cromo $(\mathrm{Cr}) \leq 200,00 \mathrm{mg} \mathrm{kg}{ }^{-1}$, mercúrio $(\mathrm{Hg}) \leq 1,00 \mathrm{mg} \mathrm{kg}^{-1}, \mathrm{Ni} \leq 70,00 \mathrm{mg} \mathrm{kg}^{-1}$, selênio $(\mathrm{Se}) \leq 80,00 \mathrm{mg} \mathrm{kg}^{-1}$, coliformes termotolerantes com número mais provável por grama de matéria seca $(\mathrm{NMP} / \mathrm{g}$ de $\mathrm{MS}) \leq 1.000,00$, ovos viáveis de helmintos com número por $4 \mathrm{~g}$ de sólidos totais $\left(\mathrm{n}^{\circ}\right.$ em $4 \mathrm{~g}$ de ST $) \leq 1,00$ e Salmonella $\mathrm{sp}$. ausente em $10 \mathrm{~g}$ de matéria seca.

Anteriormente a promulgação das normas de controle especifica de qualidade (BRASIL, 2006, 2009), os compostos de resíduo sólido urbano eram caracterizados biológica, física e quimicamente como material orgânico bastante heterogêneo, em função das matérias-primas contidas no resíduo sólido urbano, da origem (domésticos ou industriais) e da natureza (orgânica ou inorgânica) dos resíduos, da temperatura e do nível de maturação final da compostagem (BERTON e VALADARES, 1991; HE et al., 1992; CRAVO et al., 1998; EGREJA FILHO et al., 1999; ABREU-JUNIOR et al., 2005; 2009a). Até então também não havia relatos de estudos da variação temporal da qualidade de compostos de resíduo sólido urbano produzidos no Brasil, quando SILVA et al. (2005) fizeram uma comparação dos sistemas Faber-Ambra, DANO original, na unidade de reciclagem e compostagem (URC) de São José dos Campos - SP, e DANO modificado, com rotação acelerada do cilindro bioestabilizador, da URC de Vila Leopoldina, São Paulo, Capital, para faixas de variação na composição e concluíram que somente o composto obtido pelo sistema DANO original, com maturação mínima de 50 dias, apresentava qualidade compatível para uso agrícola. Todavia, quando se alterava a rotação do cilindro bioestabilizador no processo DANO, reduzindo a permanência do resíduo para 6 horas, haveria necessidade de um tempo mínimo de compostagem em leiras superior a 110 dias.

A qualidade da separação da fração inerte do resíduo sólido urbano é fator essencial e imprescindível para a obtenção de composto com características agronômicas desejáveis. Em um programa de coleta seletiva tradicional, é feita triagem pela a própria comunidade, separando os resíduos nos domicílios e estabelecimentos, e, na URC, alguns funcionários finalizam a separação, sem maquinário especial. Sem a coleta do resíduo sólido urbano orgânico em separado, a separação de inertes da fração orgânica torna-se difícil e compromete a qualidade do composto (ABREUJUNIOR et al., 2005, 2009a; SILVA et al., 2005, 2009). Assim, devem ser incentivadas políticas públicas para coleta seletiva dos resíduos sólidos e dos orgânicos, prioritariamente com a separação das respectivas frações no local de origem, por exemplo, resto de alimento separado isolada e diretamente na cozinha, pelo gerador.

Conforme dados de 2008 do Instituto Brasileiro de Geografia e Estatística - IBGE (IBGE, 2010), nos 5562 municípios com unidades de manejo de resíduos sólidos, coletaram-se $259.547 \mathrm{t} \mathrm{dia}^{-1}$ de resíduos sólidos urbanos, do quais $17,6 \%$ foram dispostos em lixões, $15,7 \%$ em aterros controlados; $64,6 \%$, em aterros sanitários; e apenas $0,63 \%$, compostados. Em relação à percentagem de resíduos encaminhados para compostagem, houve uma redução em 4,5 vezes no valor em comparação com os dados de 2000 (IBGE, 2002), quando 2,87\% dos resíduos sólidos urbanos foram compostados. Tal cenário evidencia a diminuição do número de URCs no Brasil, pelas condições inadequadas de operação e baixa qualidade dos compostos produzidos. Contudo, esse cenário deve se modificar com a promulgação da Política Nacional de Resíduos Sólidos de 2010 (BRASIL, 2010), que indica que a fração orgânica não poderá mais ser destinada a aterros sanitários. Há necessidade de realizar o tratamento da fração orgânica por compostagem ou 
incineração.

É evidente que a compostagem é a melhor opção para a reciclagem da matéria orgânica e dos nutrientes contidos no resíduo sólido urbano orgânico. Porém, é imprescindível a geração de subsídios para uma nova filosofia para geração de compostos de alta qualidade, com comprometimento do cidadão gerador do resíduo, dos órgãos de controle e dos administradores públicos. Este trabalho foi conduzido com o objetivo de avaliar a qualidade, por meio da variabilidade temporal das características químicas e do grau de maturação, de compostos de resíduos sólidos urbanos provenientes das URCs de São Matheus, Vila Leopoldina e São José dos Campos.

\section{MATERIAL E MÉTODOS}

As amostras de compostos de resíduo sólido urbano orgânico foram obtidas nas URCs de São Matheus e Vila Leopoldina, da cidade de São Paulo, e na URC de São José dos Campos, do interior do Estado de São Paulo, em leiras de composto destinado ao uso agrícola, exceto para São José dos Campos, no período de 13/08/98 a 28/04/99. As três URCs utilizavam processo semifechado de compostagem, denominado DANO (Figura 1), e tiveram o funcionamento encerrado entre os anos de 2003 e 2006.

Teoricamente, conforme descrito em Silva et al. (2009), a compostagem pelo processo DANO deveria ocorrer em duas fases: 1) no bioestabilizador (fechado) e 2) no pátio de compostagem ao ar livre. Neste processo o resíduo sólido urbano orgânico deveria ser decomposto, por via aeróbia, a partir da ação biológica de microrganismos com o dilaceramento e homogeneização do material. A umidade, aeração e $\mathrm{pH}$ deveriam ser controlados para que seus valores fossem mantidos nas faixas ótimas para a degradação dos resíduos. Todo o sistema consistia de seis etapas: recepção do resíduo sólido urbano, triagem manual, separação eletromagnética, bioestabilização, peneiramento e cura do composto. A bioestabilização deveria ser o coração do processo, onde o material orgânico seria fermentado para transformar-se em composto.

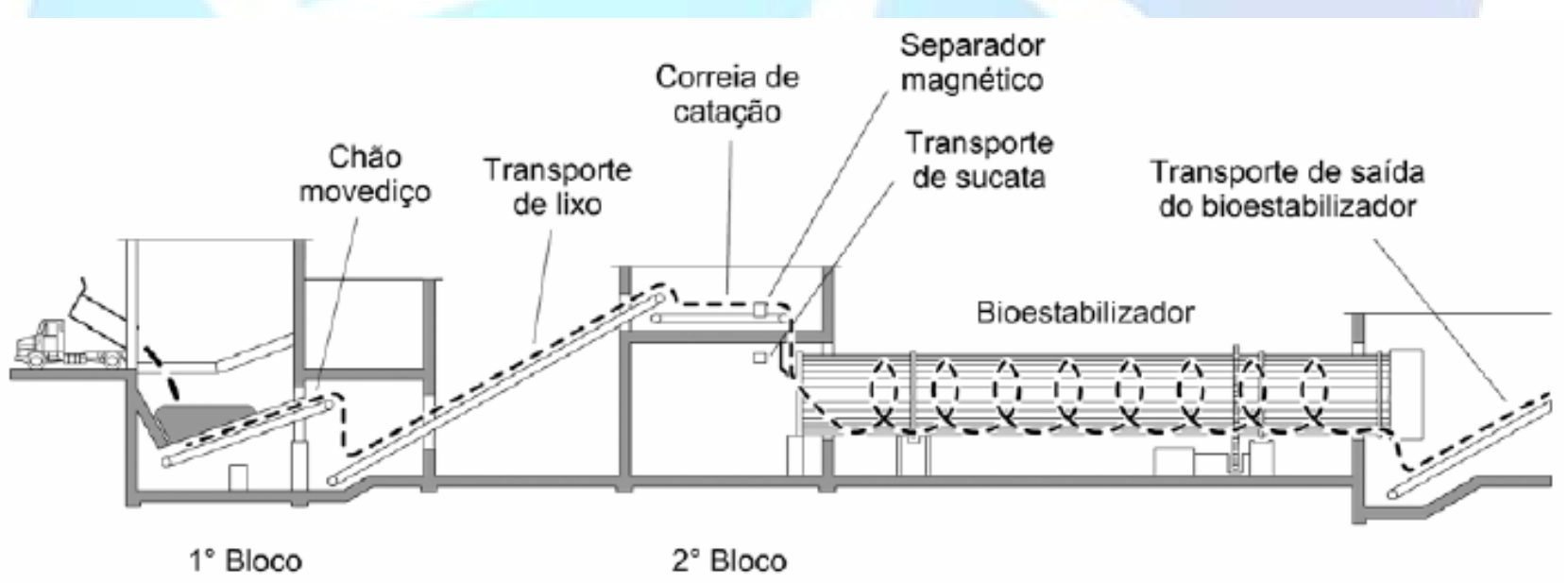

Figura 1. Sistema Dano de compostagem. Fonte: Silva et al. (2009)

Cada amostra composta, do composto original de cada URC, foi constituída de quatro amostras simples obtidas diariamente durante um período de quinze dias consecutivos, ao logo de 90 dias, totalizando 18 épocas de amostragem. Cada amostra foi armazenada em caixa plástica, de 
$180 \mathrm{~L}$ de capacidade, e enviada ao laboratório da USP/ESALQ. Cada amostra original foi homogeneizada, em betoneira, e espalhada com rastelos sobre uma lona plástica. Em seguida, uma fração de aproximadamente $20 \mathrm{~kg}$ de amostra foi recolhida e colocada para maturar, para se avaliar o grau de maturação do composto original. A fração da amostra original deixada na lona foi seca ao sol, passada em peneira de $4 \mathrm{~mm}$ de malha e novamente homogeneizada. A fração da amostra de composto separada para maturação foi colocada em caixa plástica de $60 \mathrm{~L}$ (usada normalmente para o acondicionamento de verduras e legumes, tendo seu interior revestido com tela de sombreamento), e maturada por mais 150 dias. O material contido na caixa foi revolvido e umedecido com água destilada de três em três dias, nos primeiros 120 dias; após o que a amostra foi revolvida e umedecida a cada 10 dias. Depois dos 150 dias de maturação, o composto maturado foi homogeneizado, seco ao ar, sobre lona plástica, passado em peneira de $4 \mathrm{~mm}$ de malha e novamente homogeneizado. O processo de indução de maturação das amostras do composto original foi realizado por um período de 4 meses, correspondentes aos oito períodos iniciais de amostragem do composto original nas respectivas URCs.

Para análise química de cada amostra de composto original, no total de 54 amostras (18 amostras por URC) e de composto maturado, no total de 27 amostras (9 amostras por URC), tomaram-se três subamostras, de cerca de $0,5 \mathrm{~kg}$, que foram colocadas em sacos plásticos, identificadas e armazenadas em congelador. Previamente as análises químicas, as subamostras foram descongeladas, secas em estufa com ventilação forçada a $60^{\circ} \mathrm{C}$, até peso constante, homogeneizadas, passadas em moinho do tipo Wiley, com peneira de 30 mesh, e acondicionadas em sacos plásticos devidamente identificados.

A determinação do teor de matéria orgânica nos compostos originais e maturados foi feita de modo indireto, por meio da eliminação da matéria orgânica contida nas subamostras com peróxido de hidrogênio $\left(\mathrm{H}_{2} \mathrm{O}_{2}\right) 300 \mathrm{~mL} \mathrm{~L}^{-1}$ (CHITOLINA et al., 2001). Transferiram-se 5,00 g de cada subamostra para cápsula de porcelana, previamente pesada e identificada, adicionando-se $10 \mathrm{~mL}$ de $\mathrm{H}_{2} \mathrm{O}_{2}$ e aguardando a reação de oxidação tornar-se branda. A adição de $\mathrm{H}_{2} \mathrm{O}_{2}$ foi feita de modo sucessivo até um volume final equivalente a $130 \mathrm{~mL}$ de $\mathrm{H}_{2} \mathrm{O}_{2}$. Este volume final foi considerado suficiente para a eliminação da matéria orgânica presente na subamostra, devido à ausência de borbulhamento. Posteriormente, as cápsulas foram aquecidas em banho-maria para evaporação da fase líquida ainda presente, restando um resíduo no fundo da cápsula. Pesou-se o conjunto cápsula + resíduo e obteve-se, por diferença, a quantidade de matéria orgânica de cada subamostra.

Para a análise química dos elementos contidos nos compostos originais e maturados, empregaram-se os resíduos dos materiais que restaram após o tratamento das subamostras com $\mathrm{H}_{2} \mathrm{O}_{2}$, para eliminação da matéria orgânica. Cada resíduo foi desestruturado em almofariz, homogeneizado e submetido à digestão nítrico-perclórica (CHITOLINA et al., 2001). Os extratos obtidos da digestão foram submetidos à análise química de fósforo $(\mathrm{P})$, potássio $(\mathrm{K}), \mathrm{Ca}, \mathrm{Mg}, \mathrm{S}$, alumínio ( $\mathrm{Al}$ ), $\mathrm{Fe}$, sódio ( $\mathrm{Na}$ ), $\mathrm{Cd}, \mathrm{Cr}, \mathrm{Cu}, \mathrm{Mn}, \mathrm{Ni}, \mathrm{Pb}$ e $\mathrm{Zn}$, por espectrometria de emissão atômica com plasma induzido em argônio (ICP-AES) (ABREU et al., 2009b). Empregou-se um ICP-AES da marca Jobin Yvon, modelo JY 50P simultâneo, com sistema de correção de fundo e acoplado a um amostrador automático Gilson, da Seção de Fertilidade do Solo e Nutrição de Plantas do Instituto Agronômico - IAC, da Agência Paulista de Tecnologia dos Agronegócios, da Secretaria de Agricultura e Abastecimento do Estado de São Paulo, em Campinas.

Os resultados obtidos foram analisados por meio de estatística descritiva (médias e desvio padrão), apresentados em figuras e comparados com os critérios de qualidade para fertilizante orgânico classe C (BRASIL, 2006, 2009). 


\section{RESULTADOS E DISCUSSÃO}

Ao longo do período de nove meses, os teores de carbono orgânico (Figura 2) mínimos e máximos variaram, em g kg-1, de 232 a 326, de 203 a 353 e de 238 a 327, respectivamente, para as amostras dos compostos originais das URCs São Matheus, São José dos Campos e Vila Leopoldina. Para as oito amostras dos compostos maturados, os teores mínimo e máximo de carbono orgânico variam, em g kg${ }^{-1}$, de 152 a 187, de 179 a 231 e de 171 a 249, respectivamente, para as URCs São Matheus, São José dos Campos e Vila Leopoldina, demonstrando uma diminuição no teor de carbono orgânico devido à maturação dos compostos. De modo geral, pode-se inferir que os teores de carbono orgânico foram semelhantes entre as amostras dos compostos originais das três URCs. O mesmo ocorreu para as amostras dos compostos maturados. Não obstante a variabilidade temporal, os resultados indicam que, para carbono orgânico, os compostos provenientes das diferentes URCs apresentam, aproximadamente, a mesma qualidade.

Egreja Filho (1993) avaliou as propriedades químicas de amostras do resíduo sólido urbano bruto ou bioestabilizado, oriundo da URC de Belo Horizonte, MG, que, então, foram compostadas isoladamente, ou com esterco, ou com esterco e resíduo sólido urbano de Viçosa, MG. Os resultados evidenciaram de que a compostagem da matéria orgânica do resíduo sólido urbano é seguida de diminuição do teor de carbono orgânico, da faixa de 297 a $409 \mathrm{~g} \mathrm{~kg}^{-1}$ para 226 a $259 \mathrm{~g} \mathrm{~kg}^{-1}$ (considerando teor de carbono orgânico da matéria orgânica de $58 \%$ ); e de aumento dos valores de $\mathrm{pH}$, da faixa de 4,2 a 7,6 para 7,8 a 9,9; do teor de ácidos húmicos, de 29 a $42 \mathrm{~g} \mathrm{~kg}^{-1}$ para 8,5 a $8,6 \mathrm{~g} \mathrm{~kg}^{-1}$; e da CTC, de 236 a $436 \mathrm{cmol}_{\mathrm{c}} \mathrm{kg}^{-1}$ para 546 a $646 \mathrm{cmol}_{\mathrm{c}} \mathrm{kg}^{-1}$, do material compostado. Evidências semelhantes, quanto à redução do teor de carbono ser indicativo de material inicial não estabilizado, foram relatadas por Ayuso et al. (1996), em experimento de compostagem com resíduos urbanos da região de Múrcia, Espanha, que relataram teores carbono orgânico de 236 a $295 \mathrm{~g} \mathrm{~kg}^{-1}$ nos resíduos sólidos urbanos antes da compostagem e teores de 86,3 a $117 \mathrm{~g} \mathrm{~kg}^{-1}$ nos respectivos compostos. 

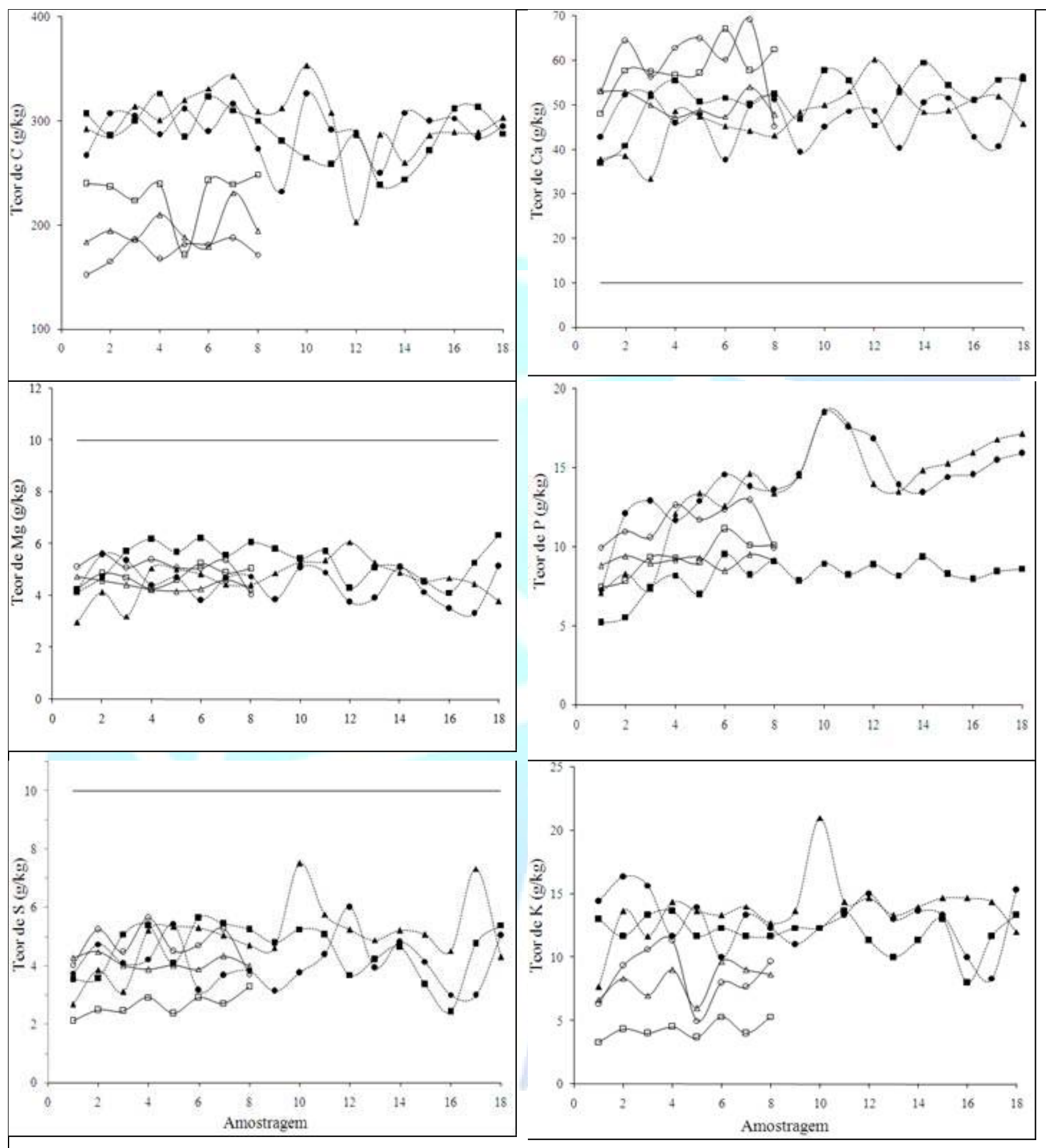

Figura 2 - Teores de carbono orgânico e macronutrientes nos resíduos sólidos urbanos (Usinas São José dos

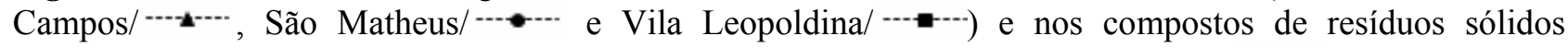
urbanos (Usinas São José dos Campos/ $\longrightarrow$, São Matheus/ $\longrightarrow$ e Vila Leopoldina/ $\longrightarrow$ ) ao longo de um período de 18 amostragens quinzenais, e os valores mínimos de macronutrientes secundários para que um fertilizante orgânico classe C possa ser declarado como fonte do nutriente, pela IN no 25/2009 (BRASIL, 2009) ( - ). 
As faixas de teores de carbono orgânico das amostras originais e das amostras compostadas do presente trabalho (Figura 2) são comparáveis às faixas de carbono orgânico das amostras de resíduos urbanos e dos respectivos compostos dos trabalhos de Egreja Filho (1993) e Ayuso et al. (1996). As amostras compostadas também apresentam teores de carbono orgânico muito semelhantes aos teores relatados por Cravo et al. (1998), para composto de Belo Horizonte, Brasília (com coleta seletiva), Florianópolis, Manaus, Rio de Janeiro e São Paulo, cujos teores de carbono orgânico foram de 93 a $193 \mathrm{~g} \mathrm{~kg}^{-1}$, excluindo o composto de Brasília sem coleta seletiva, com teor de $275 \mathrm{~g} \mathrm{~kg}^{-1}$.

Os resultados obtidos estão de acordo com observado por Silva et al. (2005), que avaliando três unidades tipo DANO, mostraram que somente o processo original, de São José dos Campos, SP, possuía produção de composto bioestabilizado e de qualidade aceitável, desde que o material fosse mantido em pátios de compostagem com períodos superiores a 50 dias de compostagem. A etapa de bioestabilização é crucial para o processo de compostagem. Nas URCs avaliadas, os bioestabilizadores foram alterados sem critérios técnicos, sendo o resíduo mantido no bioestabilizador por apenas 2 dias, na faixa termofílica de temperatura; quando o ideal seria de até 5 dias. Após a bioestabilização, o composto era passado por uma peneira de malha de $1 \mathrm{~cm}$ e estocado em pilhas para venda. Portanto, a redução no teor de carbono orgânico, ao longo do tempo de 150 dias de cura, evidencia que os compostos produzidos nas três URCs não eram compostos orgânicos propriamente ditos. Mas, representavam, sim, os respectivos resíduos sólidos urbanos recebidos por cada URC, cuja aplicação direta ao solo poderia acarretar problemas, por exemplo, de deficiência de nitrogênio às plantas devido à imobilização de nitrogênio pela biota do solo durante a fase de estabilização da matéria orgânica adicionada ao solo (ABREU-JUNIOR et al., 2005, 2009a). Não obstante, se os resíduos fossem devidamente compostados, todos os compostos apresentariam teores de carbono orgânico adequados para o registro como fertilizante orgânico Classe C (BRASIL, 2009).

Os teores de nutrientes e metais tóxicos nas amostras de compostos iniciais e curadas (Figuras 2, 3 e 4), obtidos a partir da digestão nítrico-perclórica, podem ser considerados como o equivalente aos totais dos metais presentes nos compostos, haja vista que a mistura digestora oxida totalmente a matéria orgânica e também solubiliza compostos inorgânicos insolúveis, tais como carbonatos, sulfetos, fosfatos e outros que poderiam estar presentes nos compostos. Embora esta digestão não solubilize metais precipitados ou ocluídos em silicatos, considerou-se desnecessária a destruição dos silicatos devido às seguintes razões: a) os metais associados a essa fração não oferecem risco de contaminação da fração orgânica do composto ou do ambiente (MATTHEWS, 1984) e b) a fração de silicatos em compostos de resíduo sólido urbano é relativamente baixa em comparação à orgânica e é representada, principalmente, por vidros triturados, com pequena ou quase nula capacidade de contaminar o solo por metais pesados. 


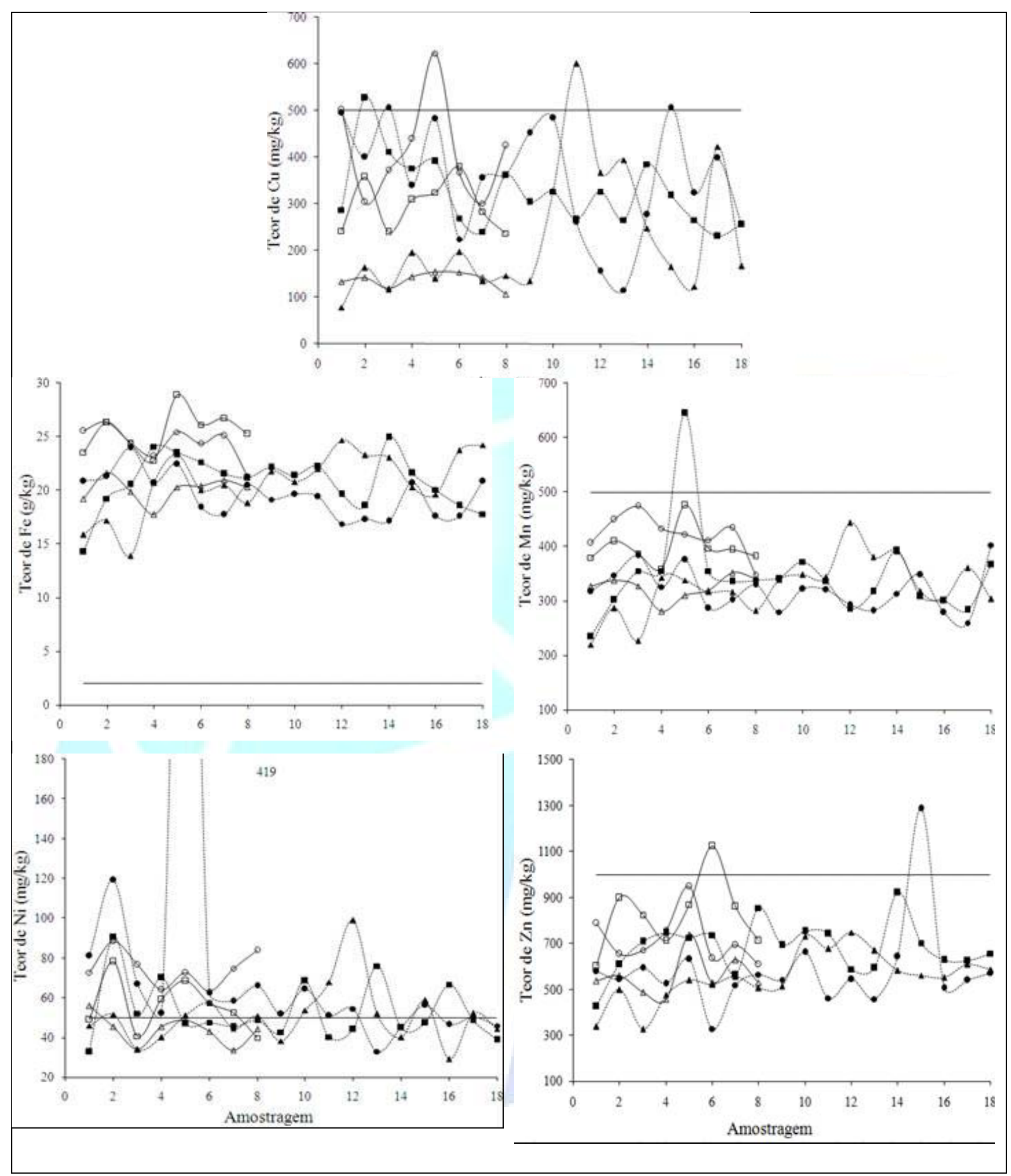

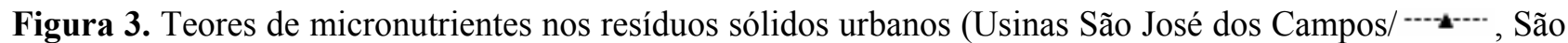

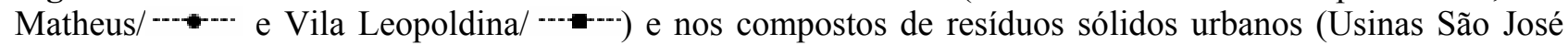
dos Campos $/ \longrightarrow$, São Matheus/ $\longrightarrow$ e Vila Leopoldina/ $\longrightarrow$ ) ao longo de um período de 18 amostragens quinzenais, e os valores mínimos de micronutrientes em um fertilizante orgânico classe C para que possa ser declarado como fonte do nutriente, pela IN nº 25/2009 (BRASIL, 2009) ( - ). 


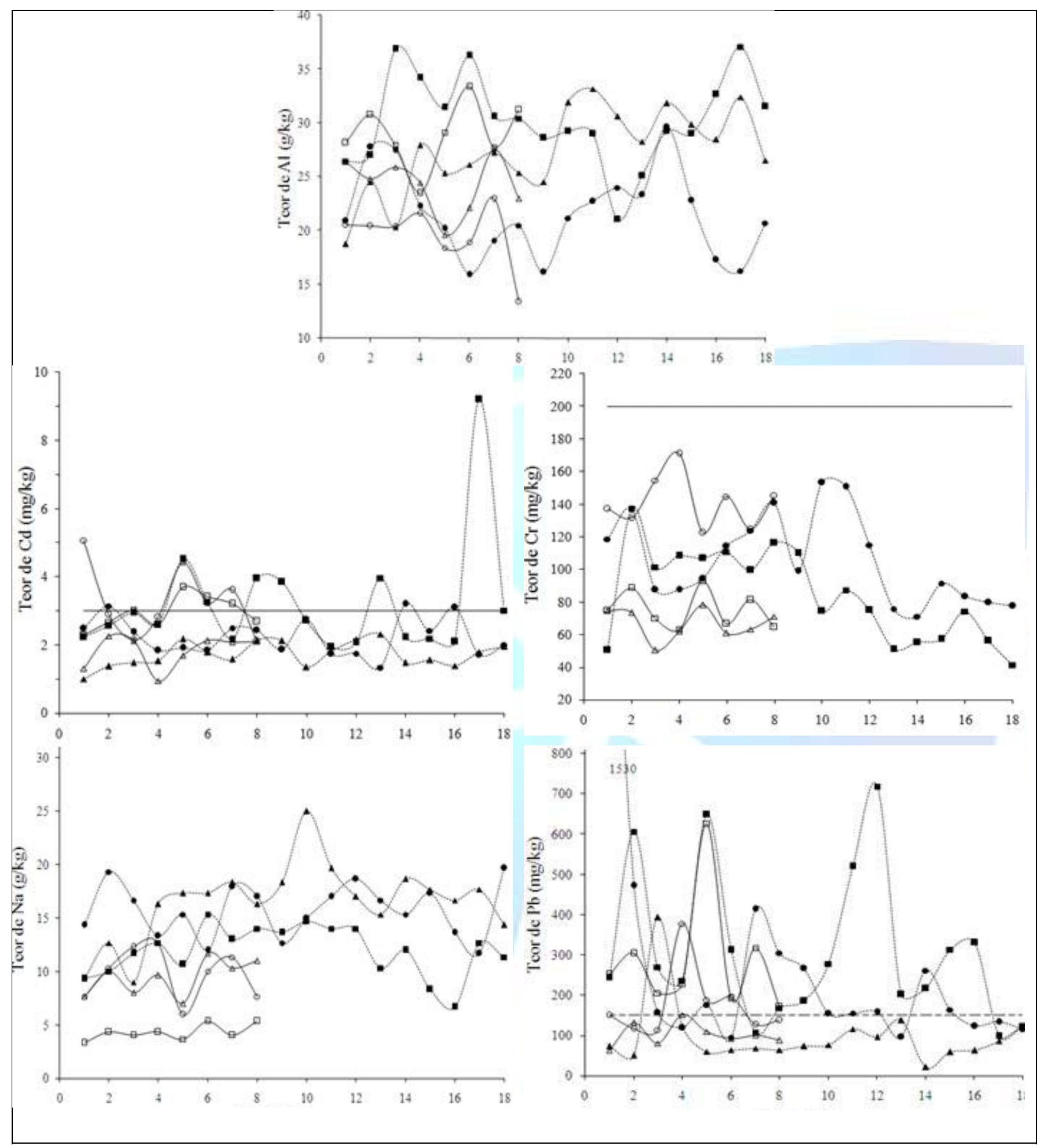

Figura 4. Teores de elementos potencialmente tóxicos nos resíduos sólidos urbanos (Usinas São José dos

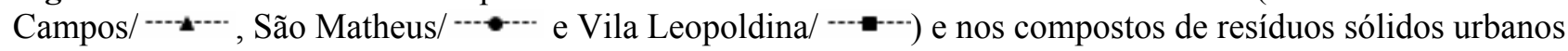
(Usinas São José dos Campos/——, São Matheus/—— e Vila Leopoldina/——) ao longo de um período de 18 amostragens quinzenais, bem como os valores máximos de contaminantes admitidos em fertilizantes orgânicos, conforme IN no 27/2006 (BRASIL, 2006) (—-). 
Os resultados das análises químicas das amostras dos compostos (Figuras 2, 3 e 4), de forma geral, evidenciaram uma menor variação e maior precisão para os elementos presentes em maiores concentrações (ex., Al, Fe e Na), considerando tanto as amostras dos compostos originais como as dos maturados, visto apresentarem coeficientes de variação baixos $(\leq 5 \%)$. Isto pode ser reflexo dos cuidados no preparo das amostras dos compostos para análise, principalmente no tocante à homogeneização de cada amostra. Entretanto, para os micronutrientes e metais tóxicos (Figuras 3 e 4), observaram-se maior variação e menor precisão, com os desvios padrão e coeficientes de variação mais elevados $(>5 \%)$.

Os teores de K (Figura 2) e Na (Figura 4), elementos solúveis em água, diminuíram com a maturação das amostras. Provavelmente, uma fração desses elementos tenham sido lixiviados pela água de irrigação das amostras em maturação. Houve aumento nos seus teores do $\mathrm{Zn}$ e de $\mathrm{Mn}$ (Figura 3) e diminuição do $\mathrm{Pb}$ (Figura 4) nos compostos maturados oriundos das URCs de São Matheus e Vila Leopoldina. Situação semelhante também foi encontrada por Grossi (1993), para vários metais pesados em compostos de resíduo sólido urbano com diferentes graus de maturação. Os demais elementos químicos, praticamente, não tiveram suas faixas de teores alteradas pela maturação das amostras. Os metais $\mathrm{Cr}, \mathrm{Cu}, \mathrm{Mn}, \mathrm{Ni}, \mathrm{Pb}$ e $\mathrm{Zn}$ (Figuras 3 e 4), tanto nas amostras de compostos crus ou maturados, apresentaram coeficientes de variação bastante elevados (10 a 50\%). Estas situações podem ser indicativas da presença de pequenas partículas de metais ou compostos contendo os metais que poderiam ter sido dissolvidos na digestão nítrico-perclórica, o que reflete a heterogeneidade e contaminação dos resíduos sólidos urbanos orgânicos e, consequentemente, dos compostos. Uma pequena partícula presente numa amostra, mas ausente em outra, poderá alterar o resultado analítico, mesmo que as amostras possam ser consideradas bem homogêneas, constituindo numa grande dificuldade concernente à amostragem representativa dos compostos. Os resultados evidenciam a ocorrência da heterogeneidade na constituição dos compostos de resíduo sólido urbano e de variabilidade temporal na constituição química dos compostos das três URCs.

O composto da URC Vila Leopoldina, apresentou teores de P menores e teores de $\mathrm{Ca}$ e $\mathrm{Mg}$ maiores nas amostras originais e teores de $\mathrm{K}$ e $\mathrm{S}$ menores que os demais compostos (Figura 2). Em ambas as condições de maturação, os teores de micronutrientes (Figura 3) e metais tóxicos (Figura 4) foram semelhantes entre os compostos das URCs Vila Leopoldina e São Matheus; porém, o composto da URC São José dos Campos apresentou os teores menores, notadamente, os de metais pesados (Figuras 3 e 4). Estes resultados evidenciam que os compostos produzidos nas URCs Vila Leopoldina e São Matheus apresentam teores de metais bem superiores aos do composto de São José dos Campos, devido à coleta seletiva do resíduo sólido urbano orgânico no município de São José dos Campos.

De modo geral, tanto para os macros e micronutrientes quanto para os metais pesados tóxicos, os resultados podem ser comparáveis aos existentes na literatura nacional (BERTON e VALADARES, 1991; EGREJA FILHO, 1993; MELO et al., 1997; CRAVO et al., 1998; SILVA et al., 2005) e internacional (HE et al., 1992, 1995; AYUSO et al., 1996). Apenas o composto da URC São José dos Campos, contudo, apresentou teores abaixo dos limites máximos admitidos de $\mathrm{Cd}$ $\left(\leq 3,00 \mathrm{mg} \mathrm{kg}^{-1}\right)$, Ni $\left(\leq 70,00 \mathrm{mg} \mathrm{kg}^{-1}\right)$ e $\mathrm{Pb}\left(\leq 150,00 \mathrm{mg} \mathrm{kg}^{-1}\right)$ para fertilizantes orgânicos classe C (BRASIL, 2006) (Figuras 3 e 4). O composto da URC São Matheus apresentou altos teores de Cd, $\mathrm{Ni}$ e $\mathrm{Pb}$. O composto da URC Vila Leopoldina apresentou, além do teor de $\mathrm{Cd}$ alto, teor de $\mathrm{Pb}$ muito alto (faixa de 174 a $627 \mathrm{mg} \mathrm{kg}^{-1}$ ). Também se destacou o teor de $\mathrm{Zn}$ nos compostos de São Matheus e Vileopoldina, com valores próximos a $1 \mathrm{~g} \mathrm{~kg}^{-1}$, ou seja, de $0,1 \%(\mathrm{~m} / \mathrm{m})$. Em trabalho sobre comparação de métodos para avaliar metais pesados em compostos produzidos nos municípios de Mococa e Adamantina, no Estado de São Paulo, Abreu et al. (1996) encontraram teores de $\mathrm{Cd}\left(0,31\right.$ a $\left.0,48 \mathrm{mg} \mathrm{kg}^{-1}\right), \mathrm{Cr}\left(31\right.$ a $\left.71 \mathrm{mg} \mathrm{kg}^{-1}\right), \mathrm{Cu}\left(75\right.$ a $\left.119 \mathrm{mg} \mathrm{kg}^{-1}\right), \mathrm{Ni}(12,5$ a $\left.43,1 \mathrm{mg} \mathrm{kg}^{-1}\right)$ e $\mathrm{Zn}\left(178\right.$ a $\left.354 \mathrm{mg} \mathrm{kg}^{-1}\right)$ inferiores aos dos observados no presente trabalho.

Ressalta-se ainda que os resultados de Abreu et al. (1996) foram obtidos usando-se três 
métodos de digestão: água régia e $\mathrm{HNO}_{3}$, com abertura das amostras em forno de microondas, e $\mathrm{HNO}_{3}+\mathrm{HClO}_{4}$, com abertura das amostras em bloco digestor, semelhante ao procedimento adotado no presente trabalho. Os menores teores de metais pesados foram obtidos através da digestão nítrico-perclórica e os maiores através da digestão com água régia, em microondas. Em testes de recuperação, usando amostra certificada, as porcentagens de recuperação para $\mathrm{Cd}, \mathrm{Cr}, \mathrm{Cu}, \mathrm{Mn}, \mathrm{Ni}$, $\mathrm{Pb}$ e $\mathrm{Zn}$ foram, respectivamente, de 114, 61, 90, 90, 76, 89, 94\%, para a água régia, e de 88, 48, 73, $67,74,86$ e $64 \%$ para $\mathrm{HNO}_{3} / \mathrm{HClO}_{4}$. Pode-se aventar que os teores apresentados nas Figuras 2,3 e 4 podem ter sido subestimados (SILVA et al., 2005). Não obstante, a eliminação prévia da matéria orgânica presente nas amostras de compostos, conforme feito no presente trabalho, poderia fazer com que a digestão $\mathrm{HNO}_{3} / \mathrm{HClO}_{4}$ tenha tido melhor eficácia.

Com base na Instrução Normativa MAPA n 27 de 2006 (BRASIL, 2006), referente aos limites máximos de contaminantes admitidos em fertilizantes orgânicos classe $\mathrm{C}$, é possível inferir que: a) apenas as amostras de composto da URC São José apresentaram valores dentro dos limites exigidos; b) nas três URCs, o teor de Cr nos compostos crus e maturados foi dentro dos limites permitidos; c) tanto para os compostos crus quanto para os maturados das URCs de São Matheus e Vila Leopoldina, as quantidades de $\mathrm{Cd}, \mathrm{Ni}$ e $\mathrm{Pb}$ ultrapassam os limites permitidos pela lei.

Com relação às garantias mínimas de macro e micronutrientes, tendo por base a Instrução Normativa $\mathrm{n}^{\mathrm{o}} 25$ de 2009 (BRASIL, 2009), foi possível verificar que nenhum dos compostos das três URCs, independentemente da maturação, apresentaram teores de $\mathrm{Mg}, \mathrm{S}, \mathrm{Zn}, \mathrm{Mn}$ e Cu (Figuras 2 e 3) passíveis de serem declarados como nutrientes, exceto, em algumas situações, o Zn para os compostos de São Matheus e, em especial, de Vila Leopoldina. Somente o Ca e o Fe, portanto, poderiam ser declarados como nutrientes nos compostos estudados.

\section{CONCLUSÕES}

Os compostos produzidos de resíduo sólido urbano nas unidades de reciclagem e compostagem (URC) de São Matheus e Vila Leopoldina, da cidade de São Paulo, não são maturados e sim apenas pré-digeridos, ou seja, são resíduo sólido urbano crus. Não obstante a variabilidade temporal, os resíduos sólidos urbanos orgânicos das URCs São Matheus e Vila Leopoldina, da cidade de São Paulo, e da URC de São José dos Campos, no Estado de São Paulo, quando devidamente compostados, proporcionam compostos com teores adequados de carbono orgânico para o registro como fertilizante orgânico Classe C.

Embora os compostos das três URCs apresentem teores mínimos de $\mathrm{Ca}$ e Fe para serem declarados como fonte destes dois nutrientes e o de $\mathrm{Cr}$ abaixo do limite máximo admitido, somente o composto da URC de São José dos Campos, oriundo de coleta seletiva, apresenta teores de Cd, $\mathrm{Ni}$ e $\mathrm{Pb}$ adequados ser registrado como fertilizante orgânico classe $\mathrm{C}$. Todos os compostos apresentam teores de $\mathrm{Mg}, \mathrm{S}, \mathrm{Zn}, \mathrm{Mn}$ e $\mathrm{Cu}$ insuficientes para que os compostos sejam declarados fontes deste nutrientes.

A coleta seletiva dos resíduos sólidos urbanos orgânicos e a compostagem com critérios técnicos são procedimentos essências para a obtenção de composto orgânico com propriedades químicas adequadas para o registro como fertilizante orgânico classe $\mathrm{C}$, agregando valor econômico aos processos de coleta seletiva e compostagem, e, consequentemente, tornando economicamente viável para os municípios a gestão dos resíduos sólidos urbanos.

\section{AGRADECIMENTOS}

À Fundação de Amparo à Pesquisa do Estado de São Paulo, FAPESP, pelo apoio financeiro. 


\section{REFERÊNCIAS}

ABREU, M.F.; BERTON, R.S.; ANDRADE, J.C.; Comparison of methods to evaluate heavy metals in organic wastes. Communication in Soil Science \& Plant Analysis, v.27, n.5-8, p.1125$1135,1996$.

ABREU-JUNIOR, C.H.; BOARETTO, A.E.; MURAOKA, T.; KIEHL, J.C. Uso agrícola de resíduos orgânicos potencialmente poluentes: propriedades químicas do solo e produção vegetal.

Tópicos em Ciência do Solo, Viçosa, v.4, p.391-479, 2005.

ABREU-JUNIOR, C.H.; PIRES, A.M.M.; COSCIONE, A.R. Utilização agrícola de composto de lixo. In: SILVA, F.C.; RODRIGUES, M.S.; BARREIRA, L.P.; PIRES, A.M.M. (Coord.). Gestão Pública de Resíduo Sólido Urbano: Compostagem e Interface Agrícola. Capitulo 7. Botucatu: FEPAF - Fundação de Estudos e Pesquisas Agrícolas e Florestais, p.123-140, 2009a.

ABREU-JUNIOR, C.H.; SILVA, C.R.; GINÉ, M.F.G.; GOMES, T.F.; BOARETTO, A.E.; MURAOKA, T.; FERNANDES, H.M.G. Análise química de metais pesados por espectrometria de massas com plasma acoplado indutivamente. In: SILVA, F.C. (Ed.). 2. ed. Manual de Análises Químicas de Solos, Plantas e Fertilizantes. Parte 2 - Análises laboratoriais, Capítulo 5. Embrapa, Brasília, p.487-536, 2009b.

AYUSO, M.; PASCUAL, J.A.; GARCIA, C.; HERNÁNDEZ, T. Evaluation of urban wastes for agricultural use. Soil Science \& Plant Nutrition, v.42, n.1, p.105-111, 1996.

BERTON, R.S.; VALADARES, J.M.A.S. Potencial agrícola do composto urbano no Estado de São Paulo. O Agronômico, v.43, n.2/3, p.87-93, 1991.

BRASIL. Instrução Normativa SDA/MAPA No 27, de 05 de junho de 2006. Diário Oficial da União, Brasília, 9 de junho de 2006. Disponível em: $<$ http://extranet.agricultura.gov.br/sislegisconsulta/consultarLegislacao.do?operacao=visualizar\&id=16951>. Acesso em: 2 jul. 2012.

BRASIL. Instrução Normativa SDA/MAPA No 28, de 27 de julho de 2007. Aprova os Métodos Analíticos Oficiais para Fertilizantes Minerais, Orgânicos, Organo-Minerais e Corretivos, disponíveis na Coordenação-Geral de Apoio Laboratorial - CGAL/SDA/MAPA, na Biblioteca Nacional de Agricultura - BINAGRI e no sítio do Ministério da Agricultura, Pecuária e Abastecimento. Disponível em:

$<$ http://www.agricultura.pr.gov.br/arquivos/File/PDF/in $28 \quad 07$ anexo.pdf $>$. Acesso em: 2 jul. 2012.

BRASIL. Instrução Normativa SDA/MAPA Nº 25, de 23 de julho de 2009. Diário Oficial da União, Brasília, 28 de julho de 2009.

BRASIL. Lei $\mathrm{n}^{\circ}$ 12.305, de 2 de agosto de 2010. Diário Oficial da União, Brasília, 3 de agosto de 2010. Institui a Política Nacional de Resíduos Sólidos. Disponível em:

$<$ http://www.planalto.gov.br/ccivil_03/_Ato2007-2010/2010/Lei/L12305.htm>. Acesso em: 2 jul. 2012.

CRAVO, M.S.; MURAOKA, T.; GINÉ, M.F. Caracterização química de compostos de lixo urbano de algumas usinas brasileiras. Revista Brasileira de Ciência do Solo, v.22, n, p.3, 547-553, 1998. 
CHITOLINA, J.C.; SILVA, F.C.; ABREU, M.F.; PALMA, F.M.S.. CARMO, J.B. Decomposição de matéria orgânica de lixo e posterior preparo de extratos nítrico-perclórico. Campinas: Embrapa Informática Agropecuária, 2001. 8p.

EGREJA FILHO, F.B.; REIS, E.L.; JORDÃO, C.P.; PEREIRA NETO, J.T. Avaliação quimiométrica da distribuição de metais pesados em composto de lixo urbano. Química Nova, v.22, n.3, p.324-328, 1999.

GROSSI, M.G.L. Avaliação da qualidade dos produtos obtidos de usina de compostagem brasileiras de lixo doméstico através da determinação de metais pesados e substâncias orgânicas tóxicas. São Paulo, 1993. 222p. Tese (Doutorado em Química) - Instituto de Química/USP, São Paulo. 1993

HARGREAVES, J.C.; ADL, M.S.; WARMAN, P.R. A review of the use of composted municipal solid waste in agriculture. Agriculture, Ecosystems and Environment, v.123, p.1-14, 2008.

HE, X.T.; TRAINA, S.J.; LOGAN, T.J. Chemical properties of municipal solid waste compost. Journal of Environmental Quality, v.21, n.3, p.318-329, 1992.

HE, X.T.; LOGAN, T.J.; TRAINA, S.J. Physical and chemical characteristics of selected U.S. municipal solid waste composts. Journal of Environmental Quality, v.24, n.4, p.543-552, 1995.

IBGE. Pesquisa Nacional de Saneamento Básico 2000. Rio de Janeiro, 2002 Disponível em: $<$ http://www.ibge.gov.br/home/estatistica/populacao/condicaodevida/pnsb/pnsb.pdf $>$. Acesso em: 2 jul. 2012.

IBGE. Pesquisa Nacional de Saneamento Básico 2008. Rio de Janeiro, 2010. Disponível em: $<$ http://www.ibge.gov.br/home/estatistica/populacao/condicaodevida/pnsb2008/PNSB 2008.pdf $>$. Acesso em: 2 jul. 2012.

JORDÃO, C.P.; KIYOHARA, R.S.; DAMASCENO, R.N.; BRUNE, W.; PEREIRA, J.L. Speciation of cadmium, copper, lead and zinc in compost from Brazilian urban solid waste treatment plant. Ciência e Cultura Journal of the Brasilian Association for the Advancement of Science, v.48, n4, p.284-287, 1996.

LAVAGNOLO, M.C. A glance at the world. Waste Management, 32 (5), pp. 1045-1049, 2012.

MATTHEWS, P.J. Control of metal application rates from sewage sludge utilization in agriculture. CRC Critical Reviews in Environmental Control. v.14, n.3, p.199-250, 1984.

MELO, W.J.; MARQUES, M.O.; SILVA, F.C.; BOARETTO, A.E. Critérios para o uso de resíduos sólidos urbanos na agricultura e impactos ambientais (compact disc). In: CONGRESSO BRASILEIRO DE CIÊNCIA DO SOLO, 26., Rio de Janeiro, 1997. Anais. Rio de Janeiro: Sociedade Brasileira de Ciência do Solo, 1997.

OLIVEIRA, F.C. Disposição de lodo de esgoto e composto de lixo urbano num Latossolo Vermelho-Amarelo cultivado com cana-de-açúcar. 2000. 247p. Tese (Doutorado) - Escola Superior de Agricultura “Luiz de Queiroz”, USP, Piracicaba, 2000. 
SILVA, F.C. da; CHITOLINA, J.C.; BALLESTERO, S.D.; VOIGTEL, S.D.S.; MELO, J.R.B. Processos de compostos de lixo e a sua qualidade como fertilizantes orgânico. Holos Environmetal: Rio Claro, v.5, n. 2, p.121-136, 2005.

SILVA, F.C.; RODRIGUES, M.S.; BARREIRA, L.P.; PIRES, A.M.M. (Coord.). Gestão Pública de Resíduo Sólido Urbano: Compostagem e Interface Agrícola. Capitulo 7. Botucatu: FEPAF Fundação de Estudos e Pesquisas Agrícolas e Florestais, p.123-140, 2009. 